\title{
Mathematical Model of 4-Quadrant DC Electric Drive with 6-Pulse Dual Converter
}

\author{
Kosmas Zdrozis \\ Department of Automation, \\ Technological Educational Institute of Thessaloniki, Thessaloniki, Greece
}

\begin{abstract}
Mathematical model simulating the operation of DC electric drive hoisting mechanism has been developed. The study illustrates the capabilities of the developed model for investigation both normal and abnormal modes of operation of the converter and the supplying voltage. Large attention was given to the thyristor converter and its firing system so that fast-proceed micro-processes occurring in the converter can be simulated with a high degree of accuracy.
\end{abstract}

Key words: Cranes, Hoisting Mechanism, Dynamic Modes, DC Electric Drive, Thyristor Dual Converter

\section{INTRODUCTION}

Although AC electric drives with frequency converters are used widely in practice more than DC drives, some well-known leading crane building companies still use DC electric drives in their constructions. It is known that hoisting drives should be capable of power regeneration in some essential modes like lowering cargoes and speed reduction at lifting. Therefore it is necessary to design a power electronic circuit (converter) so that the power regeneration could be achieved.

From this point of view, the dual converter used in DC electric drives appears to be more simple and cheaper than the converter used in AC drives which in addition to the converter used in DC drive comprises a DC link (filter) and an inverter.

\section{MODEL STRUCTURE}

The developed hoisting electric drive mathematical model takes into account the following elements:

* Three-phase voltage supply;

* Step-down transformer;

* Dual thirstier six-pulse converter;

* Firing system;

* DC separately-excited motor;

* Armature current control loop with PI regulator;

* Motor speed control loops with PI regulator;

* Three-phase half-wave controlled rectifier;

* Field current control loop with PI regulator;

* Hoisting mechanism: reduction gearbox, drum, hoisting ropes (with a given elasticity) and cargo.

In addition to the above mentioned basic elements of the model, some auxiliary blocks are used in order to simulate different types of abnormal modes of the converter and the supplying voltage and estimate their degree of danger. These like:

* Models of different abnormal modes with the ability of choosing its type, mode of operation and stating the time;

* Calculations of the rms (root-mean-square) value of the armature current during any time interval;

* Calculation of the thermal parameter $\int \mathrm{i}^{2}(\mathrm{t}) \mathrm{dt}$.

\section{DEMONSTRATION OF THE MODEL'S ABILITIES}

a) Converter operation in normal modes:

Assuming the three-phase fully-controlled bridge to be connected to a $525 \mathrm{~V}, 50 \mathrm{~Hz}$ supply, different types of loads can be connected to the rectifier output terminals. The shape of load voltage waveforms depends on the value of the firing delay angle $\alpha$ and the lead character: pure resistances $(\mathrm{R})$, resistive-inductive (R-L) or resistive-inductive with induced electromotive force $(\mathrm{R}-\mathrm{L}+\mathrm{EMF})$. It is obvious that the current waveforms are similar in shape to the voltage waveforms and are in-phase if the load is pure resistive, hence no negative voltage can appear across the load. Varying $\alpha$ from $0^{\circ}$ to $60^{\circ}$ the load current will be continuous, if $\alpha$ exceeds $60^{\circ}$ the load current will be discontinuous and some voltage pauses will appear across the load. The maximum value $\alpha_{\max }$ is $120^{\circ}$, at which the mean load voltage equals $0 \mathrm{~V}$.

We will focus on the R-L and R-L+EMF loads (motors), as these loads are widely used in practice. Here are some cases:

1) $\alpha=60^{\circ} ; R_{d}=350 h m ; L_{d}=0,2 \mathrm{H}$.

Where, $R_{d}, L_{d}$ - the load resistance and inductance, respectively. 


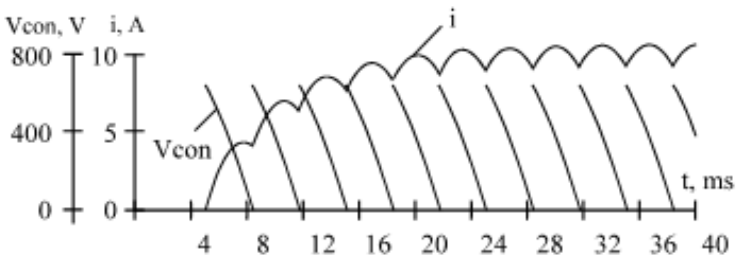

Fig. 1: Load Voltage and Current Waveform for case a. 1

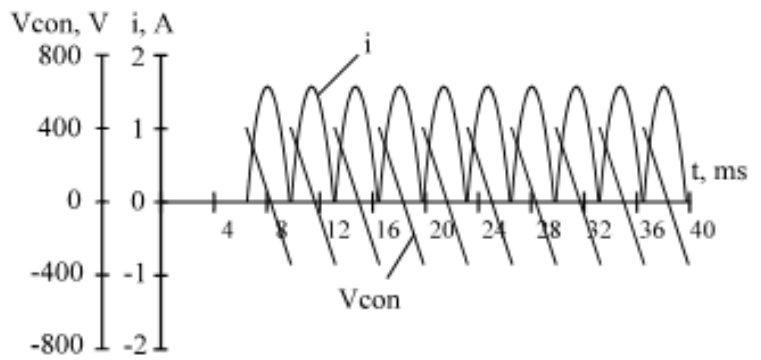

Fig. 2: Load Voltage and Current Waveform for Case a. 2

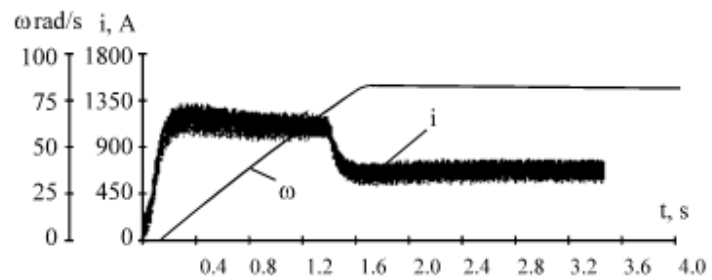

Fig. 3: Motor Current and Speed Diagram for Lifting Cargo

The load voltage $\left(\mathrm{V}_{\text {con }}\right)$ and current (i) waveforms for this case are shown in Fig. 1.

2) $\alpha=87^{\circ} ; R_{d}=35 \mathrm{Ohm} ; L_{d}=0,2 \mathrm{H}$. The load voltage $\left(\mathrm{V}_{\text {con }}\right)$ and current (i) waveforms for this case are shown in Fig. 2. It is seen that the load current falls in value very closed to zero. This means that the current is at its border value $\mathrm{I}_{\mathrm{b}}$ between the continuous and discontinuous zones.

In this case the load-current boarder mean value $\mathrm{I}_{\mathrm{b}}$ between the discontinuous and continuous current zone can be calculated using the following equation:

$$
I_{b}=\frac{V_{d d} \cdot \sin \alpha}{2 \pi \cdot f \cdot L_{d}} \cdot\left(1-\frac{\pi}{m} \cdot\left(\tan \frac{\pi}{m}\right)^{-1}\right)
$$

where, $\mathrm{V}_{\mathrm{do}}=\frac{3 \mathrm{~V}_{\mathrm{Lmax}}}{\pi} \cdot \cos \alpha-$ the maximum converter's mean voltage value, which occurs at $\alpha=0^{\circ}$.

$\mathrm{V}_{\text {lmax }}$-the maximum input line voltage. (In our case $\left.\mathrm{V}_{\text {Lmax }}=525 . \sqrt{ } 2=742,5 \mathrm{~V}\right)$;

$\mathrm{f}=50 \mathrm{~Hz}$ - the supplying voltage frequency; $\mathrm{m}=6$ - the number of converter voltage pulses. Substituting in equation 1 we get $\mathrm{I}_{\mathrm{b}}=1,048 \mathrm{~A}$.

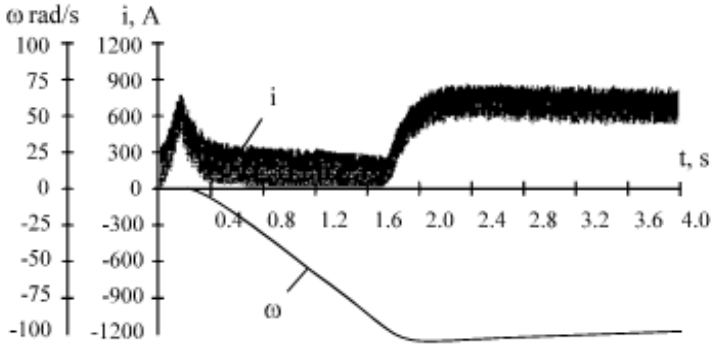

Fig. 4: Motor Current and Speed Diagram for Lowering Cargo

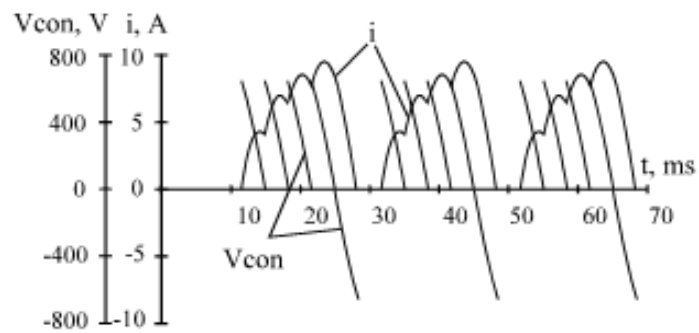

Fig. 5: Load Voltage and Current Waveform for Case b. 1

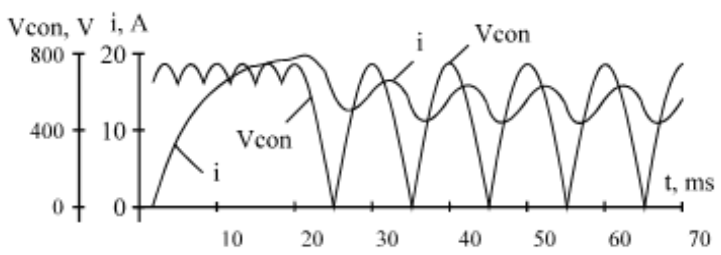

Fig. 6: Load Voltage and Current Waveform for Case b. 2

The load current average value can be calculated in the developmental model using calculated as follows:

$$
I_{a v}=\frac{1}{2 \pi} \cdot \int_{0}^{2 \pi} \mathrm{i}(\mathrm{t}) \mathrm{dt}
$$

For the current waveform shown in Fig. 2 we get $\mathrm{I}_{\mathrm{av}}=1,0482 \mathrm{~A}$, which coincides with the value calculated using equation 1 and confirms the adequacy of the developed model function.

3) The starting process of a DC separately-excited motor, connected to the converter's terminals. The motor is used in a hoisting mechanism. PI armature current and speed regulators are used in the motor control system. The armature current and motor speed diagrams for lifting and lowering the rated cargo are shown in Fig. 3 and 4, respectively.

b) Converter operation in abnormal modes: Assuming the three-phase fully-controlled bridge to be connected to the same supply given in (a), some real frequently-occurring abnormal modes of the converter 
and the source will be simulated, these like: thirstier damage, equivalent to infinite resistance in both directions and voltage source phase-failure. Here are some cases:

1. $\alpha=60^{\circ} ; R_{d}=350 h m ; L_{d}=0,2 H$. thyristor-damage will occur at the moment $\mathrm{t}=20 \mathrm{~ms}$. The load voltage $\left(\mathrm{V}_{\text {con }}\right)$ and current (i) waveforms for this case are shown in Fig. 5.

2. $\alpha=60^{\circ} ; R_{d}=350 h m ; L_{d}=0,2 \mathrm{H}$. A voltage-supply phase-failure will occur at the moment $t=20 \mathrm{~ms}$. The load voltage $\left(\mathrm{V}_{\text {con }}\right)$ and current (i) waveforms for this case are shown in Fig. 6. It's seen that the number of the voltage pulses will become 4 instead of six, this is because the model takes into account the real function of the firing system. In this case the absence of one phase will exclude two Thyristors in the same arm from the bridge circuit referring it into a bi-phase fully-controlled rectifier bridge.

\section{CONCLUSION}

As has been shown above, a mathematical model of 4-quadrant DC electric drive with 6-pulse dual converter has been developed. The model can be used for simulation of both normal and abnormal modes of the converter and the voltage supply. The model also takes into account the operation of the firing system, the real characteristics of the powerful semi-conducting devices, the elements of the closed-loop control system and the elasticity of the mechanical elements of the mechanism. The model can be very useful in determining the parameters of the protective devices of the converter.

\section{REFERENCES}

1. Green, A.W., J.T. Boys and G.F. Gates, 1988. 3phase Voltage Sourced Reversible Rectifier. Proc. IEE, 135B, 6: 362-370.

2. Inaba, H., et al., 1985. A New Speed Control System for DC Motors Using GTO Converter and Its Applications to Eelevators. IEEE Trans., IA-21, 2: 391-397.

3. Khandakji Kamal, 1998. Investigation of Converter's Abnormal Modes of Operation of DC Hoisting Drives. Electrical Engineering and Electrical Equipment.-Odessa State Polytechnic University. [ISBN 966-575-009.7], 50: 33-36.

4. Dewan, S.B., G.R. Slemon and A. Straughen, 1984. Power Semiconductor Drives. A WileyInterscience Publications. John Wiley and Sons.

5. Mummadi Veerachary, 2002. Optimal control strategy for a current source inverter fed induction motor. Computers and Electrical Engineering, Pergamon, Elsevier, 28: 255-267. 